\title{
Restorative Management of a Talon Cusp: A Case Report
}

\author{
R.Boudi", H.El Khammal, K.El Harti, B.El Mohtarim, H.Chhoul \\ Department of Pediatric and Preventive Dentistry, University Mohammed V, Rabat, Morocco
}

*Corresponding Author: R.Boudi, Department of Pediatric and Preventive Dentistry, University Mohammed V, Rabat, Morocco. Email: rachid.boudi23@gmail.com

\section{INTRODUCTION}

Talon cusp (also known as Dens evagination) is an uncommon developmental dental anomaly characterized by the existence of an accessory cusp-like structure projecting from the cingulum area or cemento-enamel junction (CEJ) of the maxillary or mandibular anterior teeth both in the primary and permanent dentition. This accessory cusp, which can vary in size, is formed by enamel and dentin, and may or may not have a projection of the pulp tissue. The maxillary lateral incisors are the most commonly affected (67\%) followed by the central incisors (24\%) and canines (9\%). This cusp is normally presented in the palatal or occlusal surfaces of the teeth. $(1,2,3,4)$

In this article, we present a case of a talon cusp that was incorrectly diagnosed as an erupting mesiodens. This case highlights the importance of early and correct diagnosis of a talon cusp so that appropriate management can be initiated.

\section{CASE Report}

A 13 year old boy, was referred to the department ofpedodontics-prevention of CCTD of Rabat for «removal of mesiodens erupted on the palatal side of the tooth 11". Medical history was without particularities.

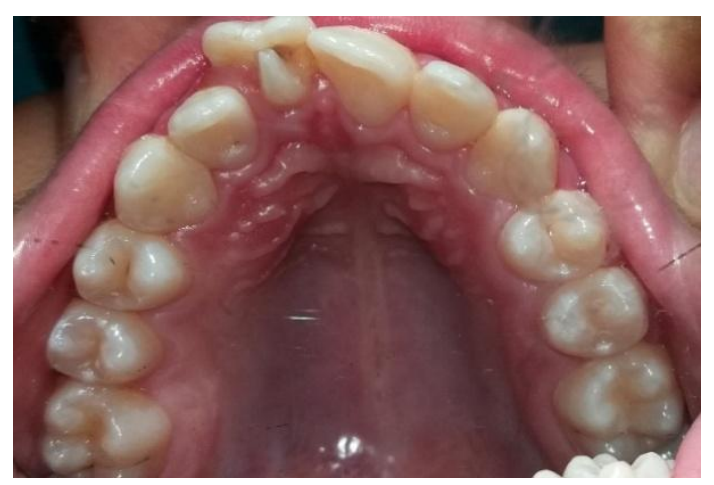

Fig1. Intra-oral photograph of the maxillary arch shows talon cuspid on the maxillary right central incisor.
The dental examination of the tooth revealed the presence on the palatal side of a pyramidal cusp accessory. (Figure 1) A cold vitality test, a percussion test and palpation were within normal limits. The tooth displayed normal physiologic movement and moved as one entity with the lingual cusp.

Two periapical $\mathrm{x}$-rays were taken at different angles.On both radiographs, tooth 11 and the anomaly appeared fused. No radiographic evidence of pathology was associated with tooth 11. We concluded then to a 'talon cusp'. (Figure 2-3)

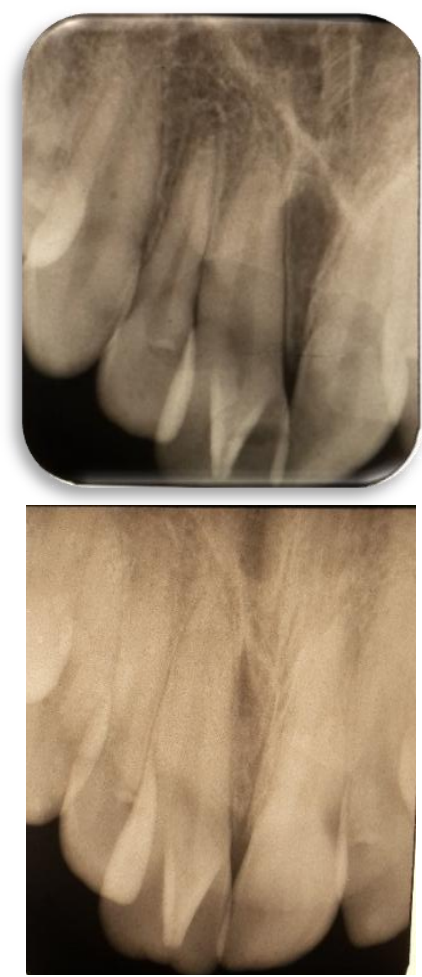

Fig 2-3. Radiographic appearance of the talon cusp The proposed treatment consisted of a gradual reduction of 'this talon cusp"in seeking a physiological cingulate anatomy, emphasizing the importance of a clinicaland $\mathrm{x}$-ray regular follow-up and rigorous oral hygiene. (Figure 4$5)$ 

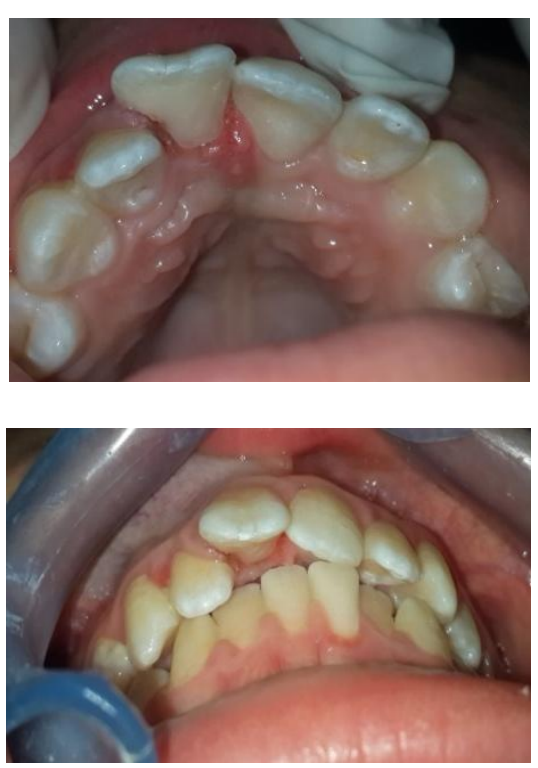

Fig 4-5. Final aspect of treatment

\section{DISCUSSION}

The anomalous talon cusp is composed of normal enamel and dentin with a varying extension of pulp tissue. It occurs more frequently in the permanent dentition than in primary dentition and shows a predilection for maxilla over the mandible. With regard to tooth affinity, only central incisors are involved in the primary dentition and the maxillary lateral incisor is most often affected in the permanent dentition (67\%), followed by the central incisors (24\%) and canines (9\%) (5).

The exact etiology of this anomaly is controversial. Genetic and environmental factors, aberrant hyperactivity of dental lamina, outward folding of the inner enamel epithelium, altered endocrine functions, and a transient focal hyperplasia of the mesenchymal dental papilla might be responsible. $(2,5)$

This anomaly have often been seen in patients with some syndromes such as: RubinsteinTaybisyndrome, Mohr syndrome, chondrodys plasia, incontinentia pigmentia chromians and Sturge- Weber-Krabbe syndrome (4)

Hattab et al. in 1996 classified it into three groups: (2)

\begin{tabular}{|l|l|l|}
\hline Type I : & Type II : & Type III \\
\hline The slightest & The moderate & The most \\
form, consists & form, is a & extreme form, \\
of a slightly & raised triangle & is a free-form \\
raised triangle & on the labial & cusp extending \\
on the labial & surface of an & from the \\
surface of an & incisor that & cement enamel \\
incisor the & extends junction to the \\
extending the & length of the & incisal edge on \\
length of the & crown, does & the labial \\
\hline
\end{tabular}

ARC Journal of Dental Science

\begin{tabular}{|c|c|c|}
\hline $\begin{array}{l}\text { crown, but not } \\
\text { reaching the } \\
\text { cementoenamel } \\
\text { junction or the } \\
\text { incisal edge. }\end{array}$ & $\begin{array}{l}\text { not reach the } \\
\text { cementoenamel } \\
\text { junction, but } \\
\text { does reach the } \\
\text { incisal edge. }\end{array}$ & $\begin{array}{l}\text { surface of an } \\
\text { incisor. }\end{array}$ \\
\hline
\end{tabular}

Furthermore, the diagnosis is important to prevent dental problems, such as caries development in the groove, periodontal problems, irritation of soft tissue, aesthetic impairment, occlusal interference resulting from tooth displacement and speech problems. The treatment planning must take into account these dental complications. (1)So in cases of premature contact and occlusal interference, the talons should be reduced gradually. (1)

Radiographically, it may appear typically as a $\mathrm{V}$-shaped radiopaque structure, as in true talon or semi-talon, or be tubercle-like, as in trace talon, originating from the cervical third of the root. The radiopaque $\mathrm{V}$-shaped structure is superimposed over the normal image of the crown of the tooth.Pulp expansion is not always visible on $\mathrm{x}$-ray, but is often present. On the $\mathrm{x}$ ray of a tooth having not erupted, the anomaly may resemble a supernumerary tooth or an odontoma. (2)

Therapeutic approach of talon cusps varies depending upon the clinical problems of each individual case. If occlusal interference presents, the cusp should be diminished gradually and periodically to look for a pulpal healing and tertiary dentin deposition.If the patient suffers of hypersensibility, topical fluorides such as fluoride varnish should be applied to the exposed dentin to reduce this hypersensibility.

Sometimes, reduction of the cusp may cause a pulpal exposure requiring partial pulpotomy for immature teeth, and root canal therapy may be indicated in more severe cases. In the case of deep developmental grooves, simple prophylactic measures such as fissure sealing can be performed if there are no caries. If caries occurs in these grooves, composite or glass ionomer restorations should be conducted. (4)

In our case, it is a "talon cuspid" on 11in the palatal surface of the right central upper permanent incisor without pulp extension which therapeutic approach consisted in gradual reduction of cusp to avoid a pulpal exposure followed by a step of dentino-pulp protection by a composite. 


\section{CONCLUSION}

The aim of this case report is to show the importance of early diagnosis and treatment which are recommended not only to improve aesthetics but also to restore the functional occlusion, prevent caries formation, and preserve the vitality of the affected tooth.

\section{REFERENCES}

[1] Talon Cusp Type I: Restorative Management Rafael Alberto dos Santos Maia, Wanessa Christine de Souza-Zaroni, , Raul Sampaio Mei, and Fernando Lamers Case Rep Dent. 2015; 2015: 425979.

[2] The reverse claw: Report of an extremely rare facial talon cusp ShruthiHegde, Shishir Ram
Shetty, and Subhas Babu ${ }^{1}$ Dent Res J (Isfahan). 2012 Sep-Oct; 9(5): 638-639.

[3] Co-Existence of Two Dens Invaginations with One Dens Evagination in a Maxillary Lateral Incisor: A Case Report Seyed Amir Satvati, Mohammad Shooriabi, Rouhollah Sharifi, Masoud Parirokh, Marzieh Saheb nasagh, and HadiAssadian J Dent (Tehran). 2014 Jul; 11(4): 485-489.

[4] Prevalence and characteristics of talon cusps in Turkish population Yeliz Guven, ${ }^{1}$ Yelda Kasimoglu, ${ }^{1}$ ElifBahar Tuna, ${ }^{1}$ Koray Gencay, ${ }^{1}$ and Oya Aktoren ${ }^{1}$ Dent Res J (Isfahan). 2016 Mar-Apr; 13(2): 145-150.

[5] Mandibular Talon Cusp in Primary Lateral Incisor: A Rare Case Report Swaminathan Kavitha, Haridoss Selva kumar, and Rajendran Barathan Case Rep Dent. 2012; 2012: 670745.

Citation: R.Boudi, H.El Khammal, K.El Harti, B.El Mohtarim, H.Chhoul. Restorative Management of a Talon Cusp: A Case Report. ARC Journal of Dental science. 2017; 2(4): 5-7. doi:dx.doi.org/10.20431/2456-0030. 0204002 .

Copyright: (1) 2017 Authors. This is an open-access article distributed under the terms of the Creative Commons Attribution License, which permits unrestricted use, distribution, and reproduction in any medium, provided the original author and source are credited. 